\title{
Health Information-Seeking Behaviors of a German Speaking Minority in Italy: Latent Class Analysis of a Population-Based Cross-Sectional Survey
}

\section{Dietmar Ausserhofer}

Institute of General Medicine, College of Healthcare Professions Claudiana, Bolzano, Italy, and Institute of Nursing Science, Department Public Health, University of Basel, Basel, Switzerland

\section{Wolfgang Wiedermann}

Department of Educational, School and Counseling Psychology, College of Education, University of Missouri, Columbia, MO, USA

Christian J. Wiedermann ( $\square$ christian.wiedermann@am-mg.claudiana.bz.it ) Institute of General Medicine, College of Healthcare Professions Claudiana, Bolzano, Italy

\section{Ulrich Becker}

4Apollis Institute of Social Research and Opinion Polling, Bolzano, Italy

\section{Anna Vögele}

Institute of General Medicine, College of Healthcare Professions Claudiana, Bolzano, Italy

Giuliano Piccoliori

Institute of General Medicine, College of Healthcare Professions Claudiana, Bolzano, Italy

Adolf Engl

Institute of General Medicine, College of Healthcare Professions Claudiana, Bolzano, Italy

\section{Research Article}

Keywords: Linguistic ethnicity, health information-seeking behaviour, population-based survey, latent class analysis

Posted Date: May 3rd, 2021

DOI: https://doi.org/10.21203/rs.3.rs-483915/v1

License: (a) (i) This work is licensed under a Creative Commons Attribution 4.0 International License.

Read Full License 


\section{Abstract}

Latent classes of health information-seeking behaviors of adults in a German-speaking minority of Italy were explored in a population-based, telephone survey on 10 health information sources conducted in South Tyrol, Italy. Data were collected from 504 adults (primary language German 68\%, Italian 28\%) and analyzed using latent class analysis and latent class multinomial logistic regression models. Three classes of health information-seeking behaviors emerged: "multidimensional" (23.3\%), "interpersonal" (38.6\%) and "technical/online" (38.1\%). Compared to the "technical/online" class, "interpersonal" class members were older, had lower education than high school, and were less likely to be of Italian ethnicity. "Multidimensional" class members were more likely to be female, older, and of German ethnicity than those in the "technical/online" class. Linguistic ethnicity explains membership in classes of healthinformation-seeking behaviour. Policy makers and healthcare providers need to consider the health information-seeking behaviors of population subgroups to promote the health literacy skills of language minority groups.

\section{Background}

Although understanding health literacy in different populations is a growing area of research, little is known about ethnolinguistic aspects of health information-seeking behavior [1-3]. The social, cultural and linguistic context is an important co-determinant of health literacy and health information-seeking behaviour because it is critical for participation and empowerment [4-6]. Health literacy refers to an individual's "knowledge, motivation, and competences to access, understand, appraise and apply information to make decisions in terms of health care, disease prevention and health promotion" [7]. Information-seeking behaviour is crucial in the design of prevention education programmes [8-10]. Low health literacy is linked to poorer health outcomes [11]. The concept of health literacy has evolved from a focus on functional skills to a focus on higher order competencies such as seeking for and critical appraisal of health information and applying it in everyday life [12]. Today, people live in a flood of health-related information [13], and media literacy education can empower critical thinking to improve the use of media to obtain health information that aids healthy living [14].

\section{Conceptual Framework}

Although evidence suggests an increasing demand that disease prevention programs and health interventions be more culturally responsive [15], few published studies have focused on health information-seeking behaviors in the context of language minorities [16-18]. South Tyrol is an autonomous region in northern Italy (total population, 524.256 people), with $69 \%$ German- and $26 \%$ Italian-speaking individuals [19]. The two ethnolinguistic groups are being served by the same health care system and service providers, which impacts health literacy as a variable of interest [20]

The main objective of this study was to assess and describe health information-seeking behaviour in the South Tyrolean population. The aims were (1) to explore latent classes of health information-seeking 
behaviors and (2) to test the association between sociodemographic characteristics (i.e. age, gender, educational level, region of origin, and ethnolinguistic group) and latent class membership.

\section{Methods}

Data are derived from a population-based cross-sectional telephone survey study. Eligibility criteria for participants were living in South Tyrol, possessing a landline (only private households, no business phones), being at least 18 years old and being declared to either the German or Italian linguistic group. According to data from the National Statistics Institute (www.dati.istat.it) for 2015, from a total of 210,000 private households in South Tyrol, 122,000 (58\%) had a landline and 208,000 (99\%) of private households had at least one mobile phone; 92,000 (44\%) solely used mobile phones. In the present study, only landline users were included since mobile phone users cannot be limited to South Tyrol. Interviews were conducted between August and September 2014 using computer-assisted telephone interviewing. Data collection was conducted by Apollis (www.apollis.it), which is a private research institution in Bolzano (BZ), Italy, conducting empirical studies for public and private clients with a focus on education, labor market topics, active aging and survey research. The goal was to conduct at least 500 interviews. A random sample of 1,445 households in South Tyrol with a landline number was contacted from professional interviewers. A total of 162 phone numbers were wrong, and 318 were not reachable at all. The remaining 965 were invited to participate in the telephone survey, and appointments for answering the phone survey were made: 458 did not participate in two of the second calls despite the appointment; for 46 , no suitable appointment was found in the study period, 53 were not capable of participating, and 359 declined. Out of 507 phone interviews, three interviews were excluded from analyses, as participants were not eligible, which resulted in a total of 504 interviews. The interviews lasted from three to 28 minutes (mean $=12$ minutes).

We assessed 10 common sources of health-related information: (1) being asked from others for advice (i.e., own knowledge), (2) magazines/newspapers, (3) TV/radio, (4) friends, (5) healthcare professionals, (6) courses, (7) medical literature, (8) random online search, (9) targeted online search in electronic databases and (10) online forums. These items were self-developed based on existing instruments and assessed on a 4-point Likert scale (ranging from $1=$ never to $4=$ often). Sociodemographic factors of participants included age (birth year), sex (male/female), mother language (German/Italian), educational level (highest degree), and region of origin (rural/urban).

\section{Ethics}

According to Italian law, approval by the Ethics Committee and written informed consent are not required in questionnaire-based and register-based population studies. The provision of information about the survey and its purpose, as well as voluntary participation at the telephone interview, provided implied consent. The study was performed in accordance with the Italian Personal Data Protection Law (Legislative Decree no. 196 of 30 June 2003) and was undertaken in accordance with the World Medical Association of Helsinki Declaration [21]. 


\section{Statistical analysis}

We used descriptive statistics, including means, standard deviations, frequencies, and cross-tabulations, to describe the health information-seeking behaviors, as well as the characteristics of the sample. To avoid biases, sampling weights based on the age and gender distributions for the population of South Tyrol according to the Provincial Statistics Institute for 2013 were employed for all analyses [19].

For the purpose of the analysis, health information indicators were dichotomized with $0=$ "never"/"rarely" and 1 = "sometimes"/"often". According to our research aims, we analyzed the data in two steps. First, we completed latent class analysis (LCA) to explore whether meaningful latent classes of peoples' health information-seeking behaviors can be identified from the 10 dichotomous health information indicators. LCA is a statistical model used to identify underlying mutually exclusive and exhaustive subgroups of individuals with shared characteristics [22]. Because the number of latent classes is a priori unknown, a series of LC models with 1 to 5 latent classes were estimated. To avoid local maxima of log-likelihoods, 1000 random starts were used for each model. To select the appropriate number of classes, the Akaike Information Criterion (AIC) and the Bayes Information Criterion (BIC) were applied (lower values indicate better model fit). In addition, unadjusted and adjusted Lo-Mendell-Rubin (LMR) tests were used to evaluate whether the $k$ class solution was superior to the $k-1$ class solution. A significant LMR test suggests that the $\mathrm{k}$ class solution better fits the data than the $\mathrm{k}-1$ class solution. In addition to the statistical indices, the interpretability of the model coefficients was inspected for each model [23]. LCA assumes that underlying latent classes explain why observed indicators are related to each other (known as the local independence assumption). Standardized bivariate residuals were used to assess potential violations of the local independence assumption.

After latent class enumeration, a latent class multinomial logistic regression model was used to predict class memberships. Note that a two-step approach (in which modally assigned LC memberships are used as dependent variables in a multinomial logistic regression) is prone to overestimating the influence of predictors [24]. Thus, after deciding upon the optimal number of classes, a one-step approach was applied where class identification and LC membership prediction were performed simultaneously [25] based on respondents' age (in years), gender $(0=$ male, $1=$ female), education $(0=$ less than high school, $1=$ high school + ), region $(0=$ urban, $1=$ rural $)$, and ethnolinguistic group $(0=$ German, $1=I t a l i a n)$. The level of significance was set at $\mathrm{P}<0.05$. Data analysis was conducted using Mplus version 7.3 [26]. Only four observations had missing values among the health information indicators. Full information maximum likelihood estimation (FIML) was applied to handle these missing data points. In addition, twenty subjects (4.0\%) had missing values in (at least) one of the covariates. No significant differences in demographics and health-information seeking behavior were observed for this small subgroup, which was thus discarded from latent class multinomial logistic regressions leaving $n=484$ subjects.

\section{Results}


Data were collected from 504 people, amounting to a response rate of $52 \%$ (nonresponse rate: $37 \%$ ). The mean age was 48.9 years; $49 \%$ of the participants were male; and the primary language German $68 \%$, Italian 28\%. The sociodemographic characteristics of the respondents are summarized in Table 1. 
Table 1

Descriptive statistics of weighted samples by ethnolinguistic group.

\begin{tabular}{|c|c|c|c|c|}
\hline \multirow[b]{2}{*}{ Variable } & & \multicolumn{3}{|c|}{ Ethno-linguistic Group } \\
\hline & & German & Italian & Total \\
\hline Age (years) & $M(S D)$ & $47.9(18.7)$ & $51.1(18.6)$ & $48.9(18.7)$ \\
\hline Sex & $n(\%)$ & & & \\
\hline Male & & $168(49.1)$ & $70(49.6)$ & $238(49.3)$ \\
\hline Female & & $174(50.9)$ & $71(50.4)$ & $245(50.7)$ \\
\hline Educational Level & $n(\%)$ & & & \\
\hline less than high school & & $210(61.2)$ & $61(43.3)$ & $271(56.0)$ \\
\hline high school + & & $133(38.8)$ & $80(56.7)$ & $213(44.0)$ \\
\hline Region & $n(\%)$ & & & \\
\hline urban & & $80(23.3)$ & $115(81.6)$ & $195(40.3)$ \\
\hline rural & & $263(76.7)$ & $26(18.4)$ & $289(59.7)$ \\
\hline \multicolumn{5}{|l|}{ Source of Information } \\
\hline Beeing asked for advice & $n(\%)$ & & & \\
\hline never/rarely & & $166(48.5)$ & $66(46.8)$ & $232(48.0)$ \\
\hline sometimes/often & & $176(51.5)$ & $75(53.2)$ & $251(52.0)$ \\
\hline Newspaper/Magazines & $n(\%)$ & & & \\
\hline never/rarely & & $105(30.7)$ & $44(31.2)$ & $149(30.8)$ \\
\hline sometimes/often & & $237(69.3)$ & $97(68.8)$ & $334(69.2)$ \\
\hline TV/Radio & $n(\%)$ & & & \\
\hline never/rarely & & $107(31.2)$ & $63(44.7)$ & $170(35.1)$ \\
\hline sometimes/often & & $236(68.8)$ & $78(55.3)$ & $314(64.9)$ \\
\hline Friends & $n(\%)$ & & & \\
\hline never/rarely & & $99(28.9)$ & $57(40.1)$ & $156(32.2)$ \\
\hline sometimes/often & & $244(71.1)$ & $85(59.9)$ & $329(67.8)$ \\
\hline Professionals & $n(\%)$ & & & \\
\hline never/rarely & & $181(52.9)$ & $59(42.8)$ & $240(50.0)$ \\
\hline
\end{tabular}




\begin{tabular}{|c|c|c|c|c|}
\hline \multirow[b]{2}{*}{ sometimes/often } & & \multicolumn{3}{|c|}{ Ethno-linguistic Group } \\
\hline & & $161(47.1)$ & 79 (57.2) & $240(50.0)$ \\
\hline Courses & $n(\%)$ & & & \\
\hline never/rarely & & $272(79.3)$ & $119(83.8)$ & $391(80.6)$ \\
\hline sometimes/often & & $71(20.7)$ & $23(16.2)$ & $94(19.4)$ \\
\hline Medical Literature & $n(\%)$ & & & \\
\hline never/rarely & & $227(66.2)$ & $102(72.3)$ & $329(68.0)$ \\
\hline sometimes/often & & $116(33.8)$ & $39(27.7)$ & $155(32.0)$ \\
\hline Random Online Search & $n(\%)$ & & & \\
\hline never/rarely & & $194(56.6)$ & 68 (47.9) & $262(54.0)$ \\
\hline sometimes/often & & $149(43.4)$ & $74(52.1)$ & $223(46.0)$ \\
\hline Targeted Online Search & $n(\%)$ & & & \\
\hline never/rarely & & $198(57.7)$ & $87(61.7)$ & $285(58.9)$ \\
\hline sometimes/often & & $145(42.3)$ & $54(38.3)$ & $199(41.1)$ \\
\hline Online Forums & $n(\%)$ & & & \\
\hline never/rarely & & $327(95.6)$ & $131(92.9)$ & $458(94.8)$ \\
\hline sometimes/often & & $15(4.4)$ & $10(7.1)$ & $25(5.2)$ \\
\hline
\end{tabular}

From the 10 health-information seeking behaviors (see Table 1), the three most frequent behaviors were seeking information in "Newspapers/Magazines" (69.2\%), from "Friends" (67.8\%), and in "Radio/TV" (64.9\%). The three less frequent health-information seeking behaviors were "Online Forums" (5.2\%), "Courses" (19.4\%), and "Medical Literature" (32.0\%).

Table 2 summarizes the LC model fit indices and estimated class sizes (based on modal assignment) for $k=1-5$ latent classes. For reasons of comparison, LC models were estimated with and without sampling weights. In general, AIC values decrease with every additional class, which hampers distinct model selection. Because this is also in line with the observation that the AIC may tend to overestimate the number of latent classes, we primarily focused on the BIC. For both weighted and unweighted LC models, the BIC favored the 3-class solution. Adjusted and unadjusted LMR tests also favored the 3-class solution when no sampling weights were used and suggested a 2-class solution when sampling weights were incorporated. Differences in parameter estimates obtained from the weighted and unweighted 3-class models were modest, and the weighted 3-class model showed an acceptable model fit $(X 2(991)=973.48$, 
$p=.648)$. Thus, overall, we decided to retain the weighted 3-class solution as the final model. Note that this model showed one significant standardized bivariate residual involving the health information sources newspapers/magazines and TV/radio. To account for this association, the final model was reestimated, allowing this residual covariance.

Table 2

Summary of latent class model fit with and without sampling weights (indices suggesting best model fit are marked bold)

\begin{tabular}{|c|c|c|c|c|c|c|c|c|c|}
\hline \multirow[b]{2}{*}{$\begin{array}{l}\text { No. of } \\
\text { classes }\end{array}$} & \multirow[b]{2}{*}{ AIC } & \multirow[b]{2}{*}{$\mathrm{BIC}$} & \multirow[b]{2}{*}{ LMR } & \multirow[b]{2}{*}{$\begin{array}{l}\text { adj. } \\
\text { LMR }\end{array}$} & \multicolumn{5}{|c|}{$\begin{array}{l}\text { Latent class sizes based on modal } \\
\text { assignment }\end{array}$} \\
\hline & & & & & LC1 & LC2 & LC3 & LC4 & LC5 \\
\hline \multicolumn{10}{|c|}{ Without sampling weights } \\
\hline 1 & 5918.6 & 5960.8 & - & - & 504 & - & - & - & - \\
\hline 2 & 5656.4 & 5745.1 & $<.0001$ & $<.0001$ & 182 & 322 & - & - & - \\
\hline 3 & 5587.0 & 5722.1 & 0.010 & 0.011 & 156 & 107 & 241 & - & - \\
\hline 4 & 5554.8 & 5736.4 & 0.213 & 0.219 & 136 & 111 & 206 & 51 & - \\
\hline 5 & 5539.8 & 5767.9 & 0.603 & 0.607 & 85 & 144 & 62 & 64 & 149 \\
\hline \multicolumn{10}{|c|}{ With sampling weights } \\
\hline 1 & 6041.1 & 6083.3 & - & - & 504 & - & - & - & - \\
\hline 2 & 5836.2 & 5924.9 & $<.001$ & $<.001$ & 222 & 282 & - & - & - \\
\hline 3 & 5771.9 & 5907.0 & 0.203 & 0.209 & 197 & 103 & 204 & - & - \\
\hline 4 & 5736.3 & 5917.9 & 0.749 & 0.749 & 127 & 125 & 142 & 110 & - \\
\hline 5 & 5714.7 & 5942.7 & 0.742 & 0.743 & 86 & 122 & 58 & 106 & 131 \\
\hline
\end{tabular}

LC-specific patterns of heath information-seeking behaviors are summarized in Fig. 1 and can be described as either "multidimensional-", "interpersonal-", or "technical/online". Members of the "multidimensional" group (23.3\%) reported performing almost all behaviors of seeking health information, ranging from exchange with friends, health professionals or other human sources to use of medical literature and electronic databases or the internet. The "interpersonal" group (38.6\%) was more likely to seek information from friends or health professionals, while the "technical/online" group (38.1\%) was more likely to use random or targeted online searches in electronic databases or the internet.

In the next step, covariates were entered into the LC model to predict latent class memberships. Descriptive characteristics for the three latent classes are summarized in Table 3. In addition to testing 
the main effects on class memberships, all potential two-way interactions were investigated [27]. Nonsignificant predictors were omitted from the model for reasons of parsimony. Findings from the latent class multinomial logistic regressions are summarized in Table 4. No significant differences were observed for urban/rural regions. Similarly, all two-way interactions were nonsignificant. Compared to the "technical/online" group, members of the "multidimensional" group were significantly more likely to be female, be older, and of German ethnicity. No difference was found for educational level. Members from the "interpersonal" group were significantly more likely to have higher age and education lower than high school and less likely to be of Italian ethnicity than those in the "technical/online" group. As displayed in Fig. 2, the probability of membership in the "technology/online" group decreases with age, whereby the probability of being a member in the "interpersonal" group increases with age. The probability of membership in the "multidimensional" group peaks at approximately 50 years of age and decreases with older age. 
Table 3

Descriptive statistics of weighted sample by latent class membership.

\section{Latent Class Membership}

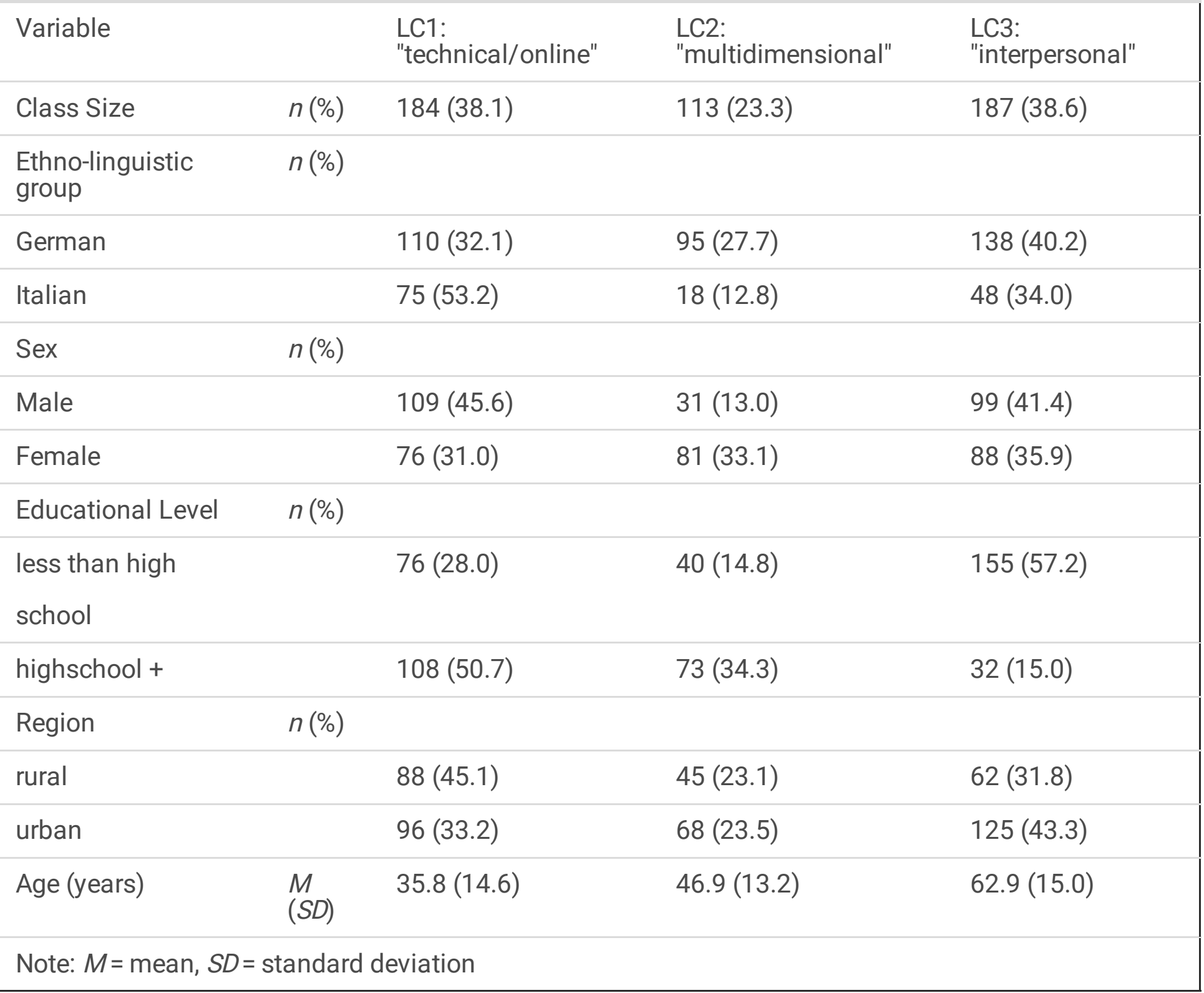


Table 4

Latent class multinomial logistic regression of patterns of health information-seeking behaviors based on weighted sample.

\begin{tabular}{|c|c|c|c|c|c|c|}
\hline & \multicolumn{3}{|c|}{ LC2: "multidimensional" } & \multicolumn{3}{|c|}{ LC3: "interpersonal" } \\
\hline & \multicolumn{3}{|c|}{$95 \% \mathrm{Cl}$} & \multicolumn{3}{|c|}{$95 \% \mathrm{Cl}$} \\
\hline Variables & OR & lower & upper & OR & lower & upper \\
\hline Sex: Female & 3.41 & 1.06 & 10.97 & 0.90 & 0.26 & 3.09 \\
\hline Age (in years) ${ }^{(a)}$ & 1.06 & 1.02 & 1.10 & 1.13 & 1.09 & 1.18 \\
\hline Ethno-linguistic group: Italian & 0.18 & 0.05 & 0.70 & 0.27 & 0.09 & 0.84 \\
\hline Educational Level: High school + & 1.75 & 0.58 & 5.25 & 0.21 & 0.08 & 0.60 \\
\hline \multicolumn{7}{|c|}{ Reference Class: LC1: "technical/online" } \\
\hline (a) mean centered & & & & & & \\
\hline
\end{tabular}

\section{Discussion}

In this study, patterns in health information-seeking behaviors in the adult population of South Tyrol revealed three health information-seeking groups in LCA, namely, "interpersonal", "technical/online", and "multidimensional". LCA is increasingly used in health literacy and prevention research [28-30]. While the "multidimensional" group of adults performed almost all behaviors of seeking health information, ranging from exchange with friends, health professionals or other human sources to use of medical literature, electronic databases and the internet, the "interpersonal" group sought information mainly from friends and/or health professionals. The "technical/online" group used random or targeted online searches in electronic databases or the internet. Class membership was explained by age, sex, level of education and ethnicity. Health information-seeking behaviors differed significantly between the two linguistic groups.

In regions with culturally and linguistically diverse backgrounds, differences in people's behavior in searching for health-related information have been described previously [31]. Language minorities may well impact health literacy in South Tyrol; for instance, drug package inserts are provided in Italian language only. In contrast to nonmedical public services established in South Tyrol for both German and Italian ethnic groups, there is a single public health care system for the entire population. Although language skills of the German-speaking minority in Italian have not been assessed in this study, only part of the population is known to be sufficiently bilingual.

Previous studies revealed that health literacy depends on a variety of factors and barriers, including language [32], social group history [33], patterns related to access and usage of digital technologies [34, 35], frequency of watching health-related television [36, 37], and involvement in social networks [38, 39]. Difficulties related to understanding health information and engaging with healthcare providers go hand 
in hand [12]. Reliance on internet-based technologies to disseminate health information and services is well known and has most recently been exemplified in the coronavirus pandemic [40-42].

Access to health information is at a particular risk, as there is a particular shortage in German-speaking health care professionals in South Tyrol, which has become a general healthcare problem in Italy today [43]. In our study, friends and healthcare professionals were two particularly important sources for providing health-related information for the German-speaking population in the "interpersonal" and the "multidimensional" LCA groups. Moreover, health professionals often have a limited understanding of health literacy levels, including health-seeking behaviors and the consequences of low health literacy for their patients [44].

Providing health-related information to adults in the "interpersonal" and the "multidimensional" groups is particularly language-dependent. Healthcare professionals need to assess the health literacy level as well as effectively communicate and consider health literacy, among other patient characteristics, when selecting patients for care management programs [35]. Health policy makers and healthcare organizations should implement interventions not only to develop health information-seeking skills in populations they serve but also to prepare healthcare professionals, e.g., general practitioners and family nurses, for better provision of information and materials that are easily accessible and understandable [35]. Critical pedagogy applied to in-service education has been shown to effectively stimulate professionals' awareness of their potential to change their practice and work environment towards improved health literacy in special linguistic contexts [18].

One-third of adults in the general South Tyrolean population reported primarily seeking health information through random or targeted online searches in electronic databases or the internet. Our study revealed that being Italian-speaking, male sex, being younger ( $<50$ years) and having higher education increased the likelihood of applying this health information-seeking behaviour. In Germany, middle and high socioeconomic status, female sex, being married or living in a stable relationship and heavy use of health-care services favor the use of the internet for health-related information [45]. As online information offers great potential to empower the population, efforts made in the South Tyrol healthcare system to improve access to online health information (e.g., eHealth services) may focus on individuals from the "interpersonal" group to enhance their capacity to use it effectively through educational programs [13].

Several limitations of this study must be taken into consideration. First, the study database is representative of the adult population (> 18 years) living in private households and using a land line phone in South Tyrol in 2014. Health literacy and health information-seeking behaviors from children and adolescents have not been investigated [46,47]. Second, with this study, we investigated only individual health information-seeking behavior. There are still few data on public health literacy, which is defined as the degree to which individuals and groups can obtain, process, understand, evaluate, and act on information needed to make public health decisions that benefit the community [48]. Thus, the impact this study may have on prevention science and public health decisions in South Tyrol is uncertain. Third, social media, which are increasingly used for the dissemination of health-related information [49], was 
not investigated in this study. Fourth, in our sample, the use of the internet as a valuable source of healthrelated information was low in both linguistic groups, which may have changed today as the survey was already performed in 2014.

In conclusion, we identified three groups of health information-seeking behaviors in the adult South Tyrolean population, i.e., "multidimensional", "interpersonal" and "technical/online". In addition to age, sex, level of education, minority language explained group membership. Compared to the "technical/online" group, members from the "interpersonal" group were significantly more likely to have higher age, education lower than high school and less likely to be of Italian ethnicity. Members of the "multidimensional" group were significantly more likely to be female, to have higher age, and to be of German ethnicity than those in the "technical/online" group.

\section{New Contribution To The Literature}

This analysis provides insight into how and where a language minority in Italy obtains health information. Policy makers and healthcare providers need to consider the information-seeking behaviors of language minority subgroups to tailor communication strategies and promote health literacy skills.

\section{Declarations}

Conflict of Interest Declaration

All authors have disclosed that they do not have any potential conflicts of interest.

\section{References}

1. Kickbusch I, Pelikan JM, Apfel F, Tsouros A: Health literacy. WHO Regional Office for Europe; 2013

2. Sørensen K, Pelikan JM, Röthlin F, Ganahl K, Slonska Z, Doyle G, et al: Health literacy in Europe: comparative results of the European health literacy survey (HLS-EU). Eur J Public Health 2015; 25:1053-8

3. Lu L, Liu J, Yuan YC: Health information seeking behaviors and source preferences between Chinese and U.S. populations. J Health Commun 2020; 25:490-500

4. Estacio EV: Health literacy and community empowerment: it is more than just reading, writing and counting. J Health Psychol 2013; 18:1056-68

5. Massey PM, Langellier BA, Sentell T, Manganello J: Nativity and language preference as drivers of health information seeking: examining differences and trends from a U.S. population-based survey. Ethn Health 2017; 22:596-609

6. Vissandjée B, Short WE, Bates K: Health and legal literacy for migrants: twinned strands woven in the cloth of social justice and the human right to health care. BMC Int Health Hum Rights 2017; 17:10 
7. Sørensen K, Van den Broucke S, Pelikan JM, Fullam J, Doyle G, Slonska Z, et al: Measuring health literacy in populations: illuminating the design and development process of the European Health Literacy Survey Questionnaire (HLS-EU-Q). BMC Public Health 2013; 13:948

8. Car J, Lang B, Colledge A, Ung C, Majeed A: Interventions for enhancing consumers' online health literacy. Cochrane Database Syst Rev 2011; CD007092.

9. Dominick GM, Friedman DB, Hoffman-Goetz L: Do we need to understand the technology to get to the science? A systematic review of the concept of computer literacy in preventive health programs. Health Educ J 2009; 68:296-313

10. Mazińska B, Struzycka I, Hryniewicz W: Surveys of public knowledge and attitudes with regard to antibiotics in Poland: Did the European Antibiotic Awareness Day campaigns change attitudes? PLoS ONE 2017; 12:e0172146

11. Berkman ND, Sheridan SL, Donahue KE, Halpern DJ, Crotty K: Low health literacy and health outcomes: an updated systematic review. Ann Intern Med 2011; 155:97-107

12. Nutbeam D, Lloyd JE: Understanding and responding to health literacy as a social determinant of health. Ann Rev Public Health 2021; 42:159-173

13. Kim H, Xie B: Health literacy in the eHealth era: A systematic review of the literature. Patient Educ Couns 2017; 100:1073-1082

14. Austin EW, Austin BW, Kaiser CK: Effects of family-centered media literacy training on family nutrition outcomes. Prev Sci 2020; 21:308-318

15. Gager PJ, Kress JS, Elias MJ: Prevention programs and special education: Considerations related to risk, social competence, and multiculturalism. J Prim Prev 1996; 16:395-412

16. Eriksson-Backa K. Elderly people, health information, and libraries: A small-scale study on seniors in a language minority. Libri 2010; 60:181-194

17. Shin Y, Maupome G: Segmentation of mexican-heritage immigrants: Acculturation typology and language preference in health information seeking. J Immigr Minor Health 2017; 19:1163-1173

18. Zanchetta MS, Maheu C, Fontaine C, Salvador-Watts L, Wong N: Awakening professionals' critical awareness of health literacy issues within a francophone linguistic-minority population in Ontario. Chronic Dis Inj Can 2014; 34:236-247.

19. Benvenuto O, Gobbi G: South Tyrol in Figs. 2014. Provincial Statistics Institute ASTAT, Autonomous Province of South Tyrol; 2014. Available from: https://astat.provinz.bz.it/downloads/Siz_2014eng.pdf

20. Eiser AR, Ellis G: Viewpoint: Cultural competence and the African American experience with health care: The case for specific content in cross-cultural education. Acad Med 2007; 82:176-183

21. World Medical Association: World Medical Association Declaration of Helsinki: ethical principles for medical research involving human subjects. JAMA 2013; 310:2191-2194

22. Hagenaars JA, McCutcheon AL: Applied latent class analysis. Cambridge University Press; 2002 
23. Marsh HW, Lüdtke O, Trautwein U, Morin AJ: Classical latent profile analysis of academic selfconcept dimensions: Synergy of person-and variable-centered approaches to theoretical models of self-concept. Struct Equ Modeling 2009; 16:191-225

24. Roeder K, Lynch KG, Nagin DS: Modeling uncertainty in latent class membership: A case study in criminology. J Am Stat Assoc 1999; 94:766-776

25. Kim S-Y: Determining the number of latent classes in single- and multiphase growth mixture models. Struct Equ Modeling 2014; 21:263-279

26. Muthén LK: Mplus users guide. Los Angeles, CA: Muthén \& Muthén; 2010

27. Sterba SK: Interpreting and testing interactions in conditional mixture models. Appl Dev Sci 2016; 20:29-43

28. Cunningham CE, Walker JR, Eastwood JD, Westra H, Rimas $H$, Chen $Y$, et al: Modeling mental health information preferences during the early adult years: a discrete choice conjoint experiment. J Health Commun 2014; 19:413-440

29. Ozawa S, Zhou M, Wonodi C, Chen H-H, Bridges JFP: Parents' preferences for interventions to improve childhood immunization uptake in northern Nigeria. Vaccine 2018; 36:2833-2841

30. Wilkerson JM, Smolenski DJ, Horvath KJ, Danilenko GP, Simon Rosser BR: Online and offline sexual health-seeking patterns of HIV-negative men who have sex with men. AIDS Behav 2010; 14:13621370

31. Mohammad A, Saini B, Chaar BB: Exploring culturally and linguistically diverse consumer needs in relation to medicines use and health information within the pharmacy setting. Res Social Adm Pharm 2015; 11:545-559

32. Beauchamp A, Buchbinder R, Dodson S, Batterham RW, Elsworth GR, McPhee C, et al: Distribution of health literacy strengths and weaknesses across socio-demographic groups: a cross-sectional survey using the Health Literacy Questionnaire (HLQ). BMC Public Health 2015; 15:678

33. De Gagne JC, Oh J, So A, Kim S-S. The healthcare experiences of Koreans living in North Carolina: A mixed methods study. Health Soc Care Community 2014; 22:417-428

34. Jackson DN, Trivedi N, Baur C: Re-prioritizing digital health and health literacy in healthy people 2030 to affect health equity. Health Commun 2020;0:1-8

35. Manganello J, Gerstner G, Pergolino K, Graham Y, Falisi A, Strogatz D: The relationship of health literacy with use of digital technology for fealth information: Implications for public health practice. $J$ Public Health Manag Pract 2017; 23:380-387

36. Duong VT, Lin I-F, Sorensen K, Pelikan JM, Van Den Broucke S, Lin Y-C, et al: Health literacy in Taiwan: A population-based study. Asia Pac J Public Health 2015; 27:871-880

37. Scopelliti M, Pacilli MG, Aquino A: TV news and COVID-19: Media influence on healthy behavior in public spaces. Int J Environ Res Public Health 2021; 18:1879

38. Kim W, Kreps GL, Shin C-N: The role of social support and social networks in health informationseeking behavior among Korean Americans: a qualitative study. Int J Equity Health 2015; 14:40 
39. Mc Grath M, Clancy K, Kenny A. An exploration of strategies used by older people to obtain information about health- and social care services in the community. Health Expect 2016; 19:11501159

40. Bodie GD, Dutta MJ: Understanding health literacy for strategic health marketing: eHealth literacy, health disparities, and the digital divide. Health Mark Q 2008; 25:175-203

41. Briones R: Harnessing the Web: How e-health and e-health literacy impact young adults' perceptions of online health information. Med 2 0. 2015; 4:e5

42. Press VG, Huisingh-Scheetz M, Arora VM: Inequities in technology contribute to disparities in COVID19 vaccine distribution. JAMA Health Forum 2021; 2:e210264

43. Di Giulio P, Basso I: [The voice of nurses on cuts and restructurations of National Health Systems]. Assist Inferm Ric 2018; 37:42-46

44. Jeong SH, Kim HK: Health literacy and barriers to health information seeking: A nationwide survey in South Korea. Patient Educ Couns 2016; 99:1880-1887

45. Nölke L, Mensing M, Krämer A, Hornberg C: Sociodemographic and health-(care-)related characteristics of online health information seekers: a cross-sectional German study. BMC Public Health 2015; 15:31

46. Fok MSM, Wong TKS: What does health literacy mean to children? Contemp Nurse 2002; 13:249258

47. Fry-Bowers EK, Maliski S, Lewis MA, Macabasco-O'Connell A, DiMatteo R: The association of health literacy, social support, self-efficacy and interpersonal interactions with health care providers in lowincome Latina mothers. J Pediatr Nurs 2014; 29:309-320

48. Freedman DA, Bess KD, Tucker HA, Boyd DL, Tuchman AM, Wallston KA: Public health literacy defined. Am J Prev Med 2009; 36:446-451.

49. Chapman E, Haby MM, Toma TS, de Bortoli MC, Illanes E, Oliveros MJ, et al: Knowledge translation strategies for dissemination with a focus on healthcare recipients: an overview of systematic reviews. Implement Sci 2020; 15:14

\section{Figures}




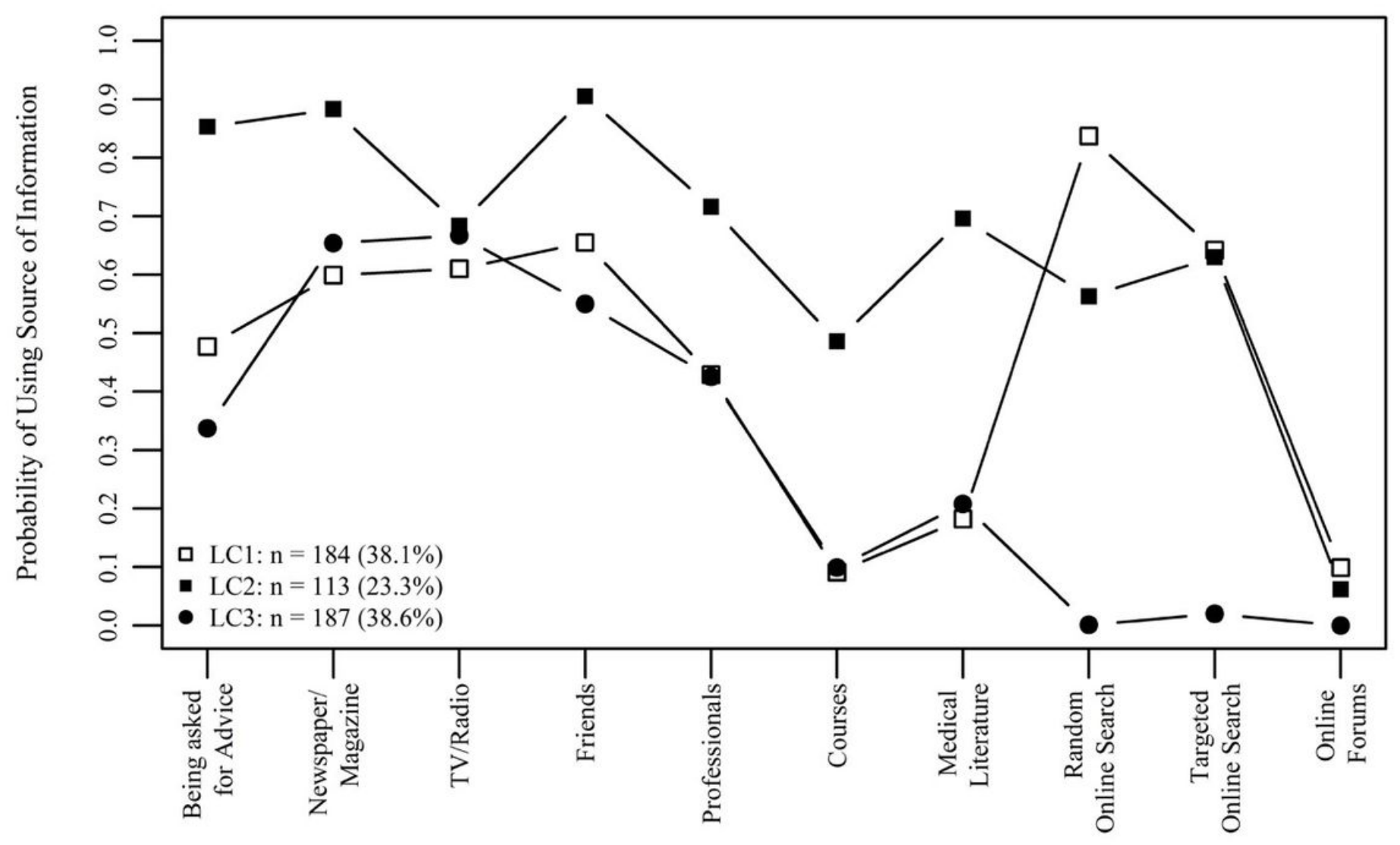

Figure 1

Sources of health information of different latent classes of information-seeking groups. LC1, "technology/online" pattern; LC2, "multidimensional" pattern; LC3, "interpersonal" pattern (based on weighted sample). 


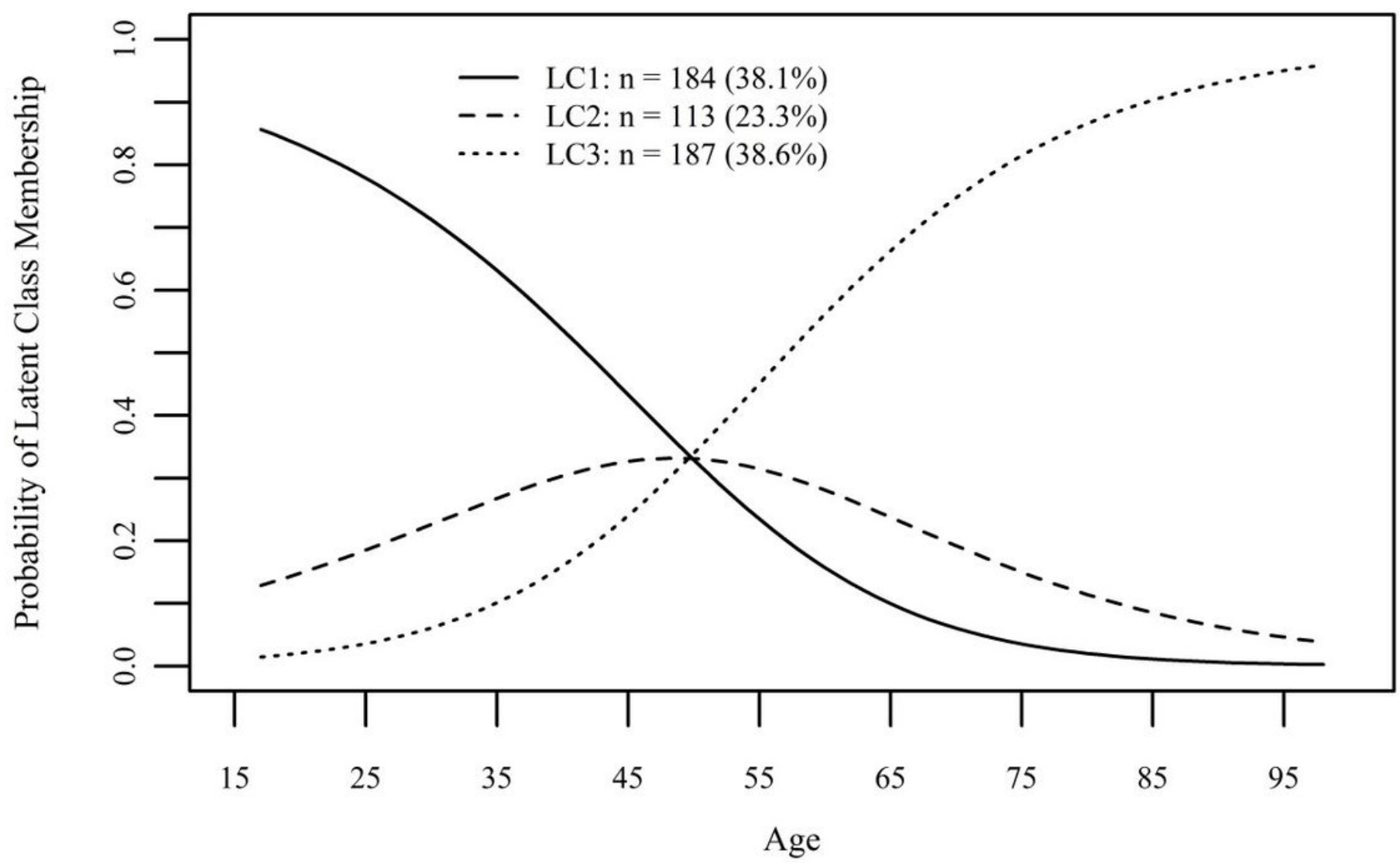

Figure 2

Age distribution of three different latent class analysis health information-seeking groups. LC1, "technology/online" pattern; LC2, "multidimensional” pattern; LC3, "interpersonal” pattern (based on weighted sample). 